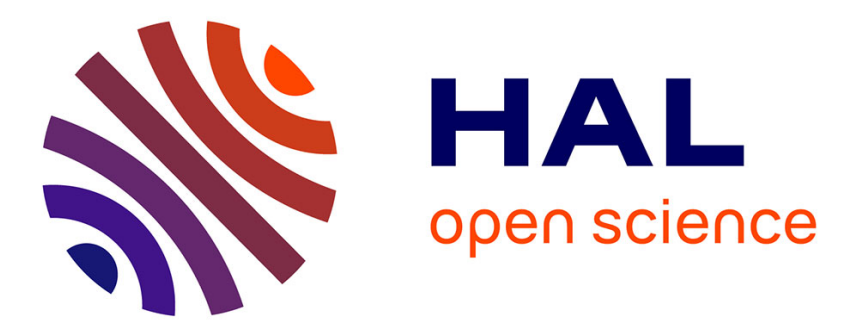

\title{
Limits of UV-light acceleration on the photooxidation of low-density polyethylene
}

\author{
Sandrine Therias, Géraldine Rapp, Claire Masson, Jean-Luc Gardette
}

\section{To cite this version:}

Sandrine Therias, Géraldine Rapp, Claire Masson, Jean-Luc Gardette. Limits of UV-light acceleration on the photooxidation of low-density polyethylene. Polymer Degradation and Stability, 2021, 183, pp.109443. 10.1016/j.polymdegradstab.2020.109443 . hal-03081995

\section{HAL Id: hal-03081995 \\ https://hal.uca.fr/hal-03081995}

Submitted on 18 Dec 2020

HAL is a multi-disciplinary open access archive for the deposit and dissemination of scientific research documents, whether they are published or not. The documents may come from teaching and research institutions in France or abroad, or from public or private research centers.
L'archive ouverte pluridisciplinaire $\mathbf{H A L}$, est destinée au dépôt et à la diffusion de documents scientifiques de niveau recherche, publiés ou non, émanant des établissements d'enseignement et de recherche français ou étrangers, des laboratoires publics ou privés. 


\title{
Limits of UV-light acceleration on the photooxidation of low-density polyethylene
}

\author{
Sandrine Therias", Géraldine Rapp, Claire Masson, Jean-Luc Gardette, \\ Université Clermont Auvergne-CNRS-SIGMA Clermont, ICCF F-63000 Clermont-Ferrand, France
}

\begin{abstract}
Lifetime prediction of polymers requires accelerated ageing based on an increase in UV light intensity and temperature. However, the representativeness of artificial ageing is still an issue. The relevance of highly accelerated UV-induced weathering raises the question of reciprocity failure depending on the polymer. The influences of irradiance and temperature on the photooxidation kinetics of polyethylene were studied to determine the extent to which increasing light intensity leads to accelerated photooxidation of polyethylene. Polyethylene films were subjected to accelerated photooxidative experiments at various UV light intensities and different temperatures, and the amounts of carbonylated photoproducts were monitored by IR spectroscopy. The results show reciprocity failure for polyethylene photooxidation and the limits of acceleration by UV light.
\end{abstract}

Keywords: polyethylene, photooxidation, irradiance, acceleration, reciprocity

\footnotetext{
* Corresponding Author: Sandrine Therias

I.C.C.F. UMR 6296 - Institut de Chimie de Clermont-Ferrand

Université Clermont Auvergne - CNRS - SIGMA Clermont

Campus des Cézeaux - 24, avenue Blaise Pascal - TSA 60026 - CS 60026

63178 Aubière Cedex

E-mail: sandrine.therias@uca.fr
} 


\section{Introduction}

The issue of lifetime prediction of polymeric materials has been a major concern for decades. Laboratory studies based on artificial ageing are required for proper determination of the long-term durability of polymers. Despite the long-term effort of various laboratories and industrial R\&D centres, the reliable and accurate prediction of polymer lifetime is still an issue. Acceleration of UV light-induced degradation of polymers requires devices which allow working at intensities much higher than the solar light intensity. Experiments for predicting the environmental durability are based on accelerated artificial ageing methods, in which the acceleration is usually obtained by increasing the intensity of the light impinging on the surface and increasing the temperature of the exposed samples. Testing in these accelerated conditions can provide useful information in shorter time periods, but the stresses (light, heat,...) and their intensity have to be chosen accurately to avoid unrealistic degradation modes and failure mechanisms not observed in "true" environmental conditions $[1,2]$. There are many sources of misleading and erroneous results. Understanding the sources of errors is mandatory for developing relevant testing methods $[3,4,5,6,7]$.

The issue of the representativeness of accelerated artificial ageing has been the object of many papers published in the scientific literature. Accurate prediction of the durability of polymers and data indicating that the material is capable of fulfilling its expected service requirement safely are of crucial importance.

Studies focusing on the influence of temperature on thermooxidative degradation have gained considerable attention for years [8]. Thermal degradation will not be considered in this article. It is often reported that the chemical processes governing thermal oxidation follow Arrhenius behaviour, although there is evidence that some polymers show curvature in the Arrhenius plot of oxidation rates [9]. It must also be considered that increasing the temperature of the samples during the experiments can cause heterogeneous degradation due to diffusion-limited oxidation. This issue is also well documented and has been reported in a large number of scientific papers $[10,11]$.

In the case of the reactions produced via light exposure, the situation is more complex. The accelerated ageing methods use commercial devices for accelerated weathering or homemade constructed devices. The acceleration of ageing is usually obtained by increasing the intensity of the UV light and by simultaneously increasing the temperature of the exposed samples. Once again, the main question is the representativeness of the accelerated ageing experiments for various reasons.

The mechanism of photooxidation can be wavelength-dependent. Most papers agree with the fact that light sources emitting short wavelengths, which are not present in sunlight, have to be rejected. The difference between the harshness of short and long wavelengths in the UV and visible domains of the solar radiation spectrum is well understood and documented in the literature $[12,13,14]$. In 
addition to the influence of the light distribution on the mechanism, it must also be recalled that the rate of photooxidation can be wavelength-dependent and thus may vary with the spectral distribution of the irradiation.

Increasing the intensity of UV light may be the cause of errors when predicting the lifetime. Light sources with excessively high intensities (lasers) should be avoided, since this kind of source may produce biphotonic processes, triplet-triplet annihilation, or excessive radicals recombinations, producing results similar to those obtained when using sources with short wavelengths. This causes ageing mechanisms not observed in natural conditions The light intensities used in conventional accelerated weathering devices are, however, well below the level which would cause a significant amount of these processes associated with pulsed lasers. Previous results published some years ago unambiguously showed that the photooxidative rate depends on the light intensity $[15,16,17]$. However, it remains a fact that the effect of irradiance, even in acceptable ranges of light intensity, is still the object of severe debates. Currently, there is a growing interest regarding this issue [18, $19,20,21,22$ ] because of the technical, economic and environmental problems arising from the degradation of polymers.

Special attention must be paid to ensure that there is no change between the mechanisms of the accelerated tests and outdoor exposure. Nonlinear oxidative degradation would be expected if diffusion of oxygen into the sample, additive migration, or other thermally controlled reactions become the rate-limiting step. Although this is a well-documented area, the effect of irradiance, even if not producing heterogeneous oxidation and remaining in acceptable ranges of wavelengths and light intensity, is not understood well and is still the object of severe debates.

In the presence of light and air, light induces photochemical reactions, which can be described by a classical chain oxidation mechanism. The global photooxidation processes depend upon both the effective irradiance and the temperature. Photooxidation is thermally activated, with activation energies on the order of a few tens of $\mathrm{kJ} / \mathrm{mol}$. Increasing the temperature allows for accelerating the photooxidation processes, and it also allows maintaining a relevant balance between the photochemical processes and thermodegradation. This is important in the case of polymers susceptible to parallel modification provoked by light or by temperature $[23,24,25]$.

The effect of irradiance on the rate of a photochemical process can be characterized by the reciprocity. A material obeys reciprocity if the degradation is a function of the total radiant energy and not a function of the rate at which the energy is applied. The reciprocity law can be described as:

$$
\mathrm{It}=\text { constant } \text {, with } \mathrm{I}=\text { irradiance and } \mathrm{t}=\text { exposure time. }
$$

The rates of photochemical processes as a function of light intensity usually follow the Schwarzschild law [26]:

$$
\mathrm{k}=\mathrm{A} \mathrm{I}^{\mathrm{p}}
$$


where $\mathrm{k}$ is the reaction rate, $\mathrm{A}$ is a proportionality constant, I is intensity (or irradiance), and $\mathrm{p}$ is the Schwarzschild coefficient, which is an experimentally derived number. This may also be written as:

$$
I^{p} t=\text { constant }
$$

When $p=1$, Schwarzschild's law becomes the reciprocity law. For most (unstabilized, stabilized or pigmented) polymeric systems, the literature reports that the p-coefficient ranges between 0.5 and 1 [18]. However, it has to be considered that most reciprocity experiments reported were conducted with commercial, stabilized or pigmented materials and, more importantly, most of the studies on the effect of irradiance and/or temperature reported in the literature focus on properties such as colour change and yellowing, gloss loss, crystallinity, modulus, elongation at break, and mechanical properties $[20,27,28]$. These properties are interesting from a practical point of view, but the changes in these properties are not a direct consequence of UV light degradation and in most cases involve several processes, some of which are not light-dependent. A unique and clear relationship between the degradation of the polymers properties and the chemistry which is involved is still an issue [29]. This makes the understanding of degradation more complex and prevents researchers from proposing general concepts.

Therefore we focused on the influence of the extent of the applied stresses (light, temperature) on the most primary detectable events, which are the chemical reactions involved in the degradation of the properties.

Reciprocity failure occurs when the coefficient of proportionality changes with light intensity. This is critical in lifetime prediction because light is usually applied at a high and constant irradiance during testing, while in general, the usage conditions are lower irradiance and cycles of light exposure. As recalled above, in most cases, the light intensities used in conventional accelerated weathering devices are well below the level which would cause a significant amount of undesired processes.

In the present study, we focused on the photodegradation of polyethylene, a widely used polymer whose degradation mechanisms are well known. This paper reports a study of the influence of light intensity on the rate of photooxidation of polyethylene. Chemical modification provoked by UV light was characterized by infrared spectrometry measurements. We also present results on the photodegradation of bisphenol A polycarbonate (PC) and poly(ethyleneterephthalate) (PET). The long-term objective is to define the limits and accuracy of accelerated weathering of polyethylene and to discuss the relevance of "highly" accelerated UV weathering tools. 


\section{Experimental}

\subsection{Materials}

Linear low-density polyethylene (LLDPE) was supplied by SABIC ${ }^{\circ}$ (LLDPE 324CE, density $=924 \mathrm{~kg} \cdot \mathrm{m}^{-3}$, $M_{w}=73,000 \mathrm{~g} \cdot \mathrm{mol}^{-1}$ ) (description in reference [30]).

PC was purchased from Aldrich $\left(M_{w}=64,000 \mathrm{~g} \cdot \mathrm{mol}^{-1}\right)$.

PET films were kindly supplied by Toray Film Europe (Miribel-France) in the form of thin, uniform films with thicknesses of 125 microns.

\subsection{Preparation of polymer films}

LLDPE films with different thicknesses (from 50 to 130 microns) were obtained by compressionmoulding of LLDPE pellets at $140^{\circ}$ and 200 bar.

PC films (100 microns) were obtained by compression-moulding of PC pellets at $200^{\circ} \mathrm{C}$ and 200 bar.

\subsection{Photothermal ageing}

The samples were irradiated in a MHE unit (Atlas/Ametek) at different temperatures ranging from 51 and $65^{\circ} \mathrm{C}$ at different irradiances (from 1.1 to $300 \mathrm{~W} \cdot \mathrm{m}^{-2}$ between 300 and $415 \mathrm{~nm}$ - see below). Three films of the polymer sample per ageing time were prepared and characterized to ensure the reproducibility of the spectrometry measurements.

This SEPAP MHE was equipped with a medium-pressure mercury lamp located in the centre of the apparatus, around which the samples were placed on a rotating carrousel. Wavelengths below 300 $\mathrm{nm}$ were filtered out. The irradiance between 300 and $415 \mathrm{~nm}$ was fixed at 90 ( $M$ mode) or 300 W.m ${ }^{2}$ ( $\mathrm{H}$ mode). Irradiance and Black Standard Temperature ( $\mathrm{T}_{\mathrm{BST}}$ ) were on-rack controlled by a wireless XENOSENSIV light and a BST monitor. The temperature of the air in the device $\left(T_{c h}\right)$ was controlled by a captor placed inside the chamber. As the polymer films used in this study were transparent, the temperature on the surface of the films was considered equal to the chamber temperature.

The light intensity can be modulated by filters. Neutral density filters were used to reduce the amount of light impinging on the polymer samples. The use of neutral density filters (blocking wavelength range: $250-700 \mathrm{~nm}$ ) allowed for carrying out experiments with irradiances below 90 W. $\mathrm{m}^{-2}$. Neutral density filters were placed in front of the polymer films in the MHE device working at $90 \mathrm{~W} \cdot \mathrm{m}^{-2}$, so that the irradiance received by the samples could be attenuated to $1.1 \mathrm{~W} \cdot \mathrm{m}^{-2}$. The filters had been obtained from MTO, and were $5 \mathrm{~cm}$ square. The measured transmission at $340 \mathrm{~nm}$ is shown in Table 1. The transparency of the filters was constant in the range of wavelengths 300-500 $\mathrm{nm}$. It has also to be noted that the transparency was not modified after exposure to light. 
Table 1 - Spectral characteristics of the neutral density filters and irradiance received by the films.

\begin{tabular}{|c|c|}
\hline $\begin{array}{c}\text { Transmittance (\%) of the filter } \\
\text { 1.2 }\end{array}$ & $\begin{array}{c}\text { Irradiance (W. } \mathrm{m}^{-2} \text { ) received by the } \\
\text { films }\end{array}$ \\
\hline 11.8 & 1.1 \\
\hline 14.1 & 10.6 \\
\hline 25.5 & 12.7 \\
\hline 46.1 & 23.0 \\
\hline
\end{tabular}

\subsection{Characterization method}

\section{IR spectroscopy}

The thickness of the samples was low enough to allow for monitoring the chemical changes in transmission mode. This mode of detection offers the great advantage of quantitative values, in contrast to the ATR mode, which is sensitive to the surface quality, requires internal corrections and only yields semi-quantitative information. The spectra were recorded with a Nicolet 6700 FTIR spectrometer working with OMNIC software. The spectra were obtained using 32 scans and a $2 \mathrm{~cm}^{-1}$ resolution.

\section{Results and discussion}

Infrared spectroscopy has proven to be a useful and is frequently used analytical technique for monitoring the oxidation process of polyethylene [31]. Figure 1 illustrates the changes to the LLDPE spectra, which occurred during the photooxidation, in the range of the carbonyl absorption. 


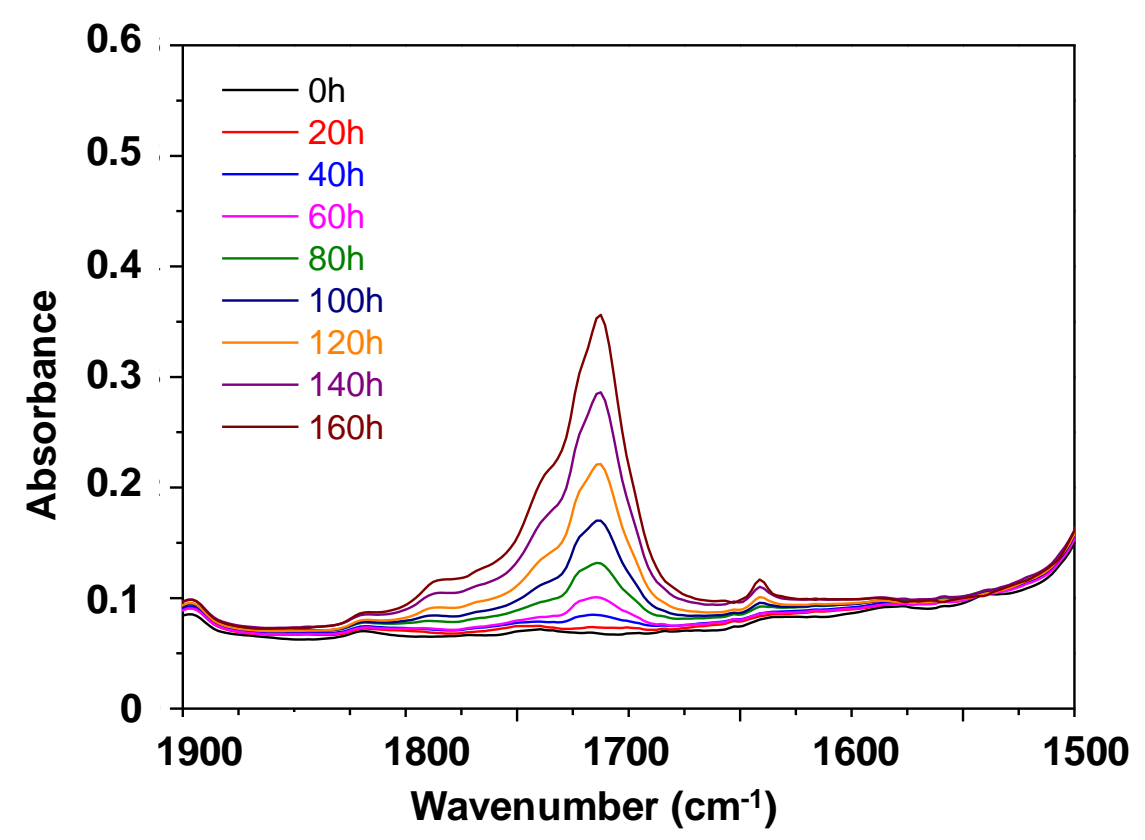

Figure 1: Infrared spectra of a LLDPE film (80 microns) at different times of photooxidation in the MHE device $\left(90 \mathrm{~W} \cdot \mathrm{m}^{-2}\right.$ and $60^{\circ} \mathrm{C}$ )

The changes in the spectrum indicate that ketones $\left(1718 \mathrm{~cm}^{-1}\right)$ are formed during the initial steps, and carboxylic acids $\left(1713 \mathrm{~cm}^{-1}\right)$, esters $\left(1735 \mathrm{~cm}^{-1}\right)$ and lactones $\left(1780 \mathrm{~cm}^{-1}\right)$ are formed during secondary processes. One can also notice the formation of isolated double bonds $\left(1640 \mathrm{~cm}^{-1}\right)$. In the range of hydroxyl frequencies, not shown here, a broad band with a maximum at $3420 \mathrm{~cm}^{-1}$ and a sharp absorption band at $3550 \mathrm{~cm}^{-1}$ appeared in the spectrum. These bands were attributed to the formation of monomeric hydroperoxides $\left(3550 \mathrm{~cm}^{-1}\right)$ and hydrogen-bonded alcohols and hydroperoxides $\left(3420 \mathrm{~cm}^{-1}\right)$. The intensities of both bands remained very low, confirming that the stationary concentrations of hydroperoxides were rather small under the conditions of photooxidation [32]. At present, the mechanism of photooxidation accounting for the main routes of degradation of LLDPE is fairly well understood. LLDPE is a non-absorbing polymer in the sense that it does not contain chromophoric functions in its chemical structure, which can absorb in the range of solar light. The basic law of photochemistry should be recalled: light absorption is necessary to provoke photochemical reactions. In the case of non-absorbing polymers, the absorption of light is attributed to unidentified chromophores, which can vary from one LLDPE to another. Extensive work has been devoted to the nature of chromophoric species $[33,34,35]$ and it is well known that oxidized species formed during processing, such as hydroperoxides or ketones, are potential 
candidates. Light absorption by chromophoric defects results in the formation of radicals, which can react following different pathways: abstraction of a hydrogen atom from the macromolecular chain, addition to an unsaturated group (crosslinking reaction [36]), or addition to oxygen, which leads to the formation of various products as recalled above (Fig.1). The intensity of the band at $1713 \mathrm{~cm}^{-1}$ is often used as a measure of the concentration of carbonyl compounds (mainly carboxylic acids) and to quantify the extent of the oxidation [35]. The slight differences in the film thicknesses between the various samples were corrected by adjusting the absorbance at $720 \mathrm{~cm}^{-1}$.

\subsection{Influence of irradiance $\left(90\right.$ and $\left.300 \mathrm{~W} . \mathrm{m}^{-2}\right)$ at a constant temperature}

We evaluated the influence of the irradiance on the oxidation of samples with a thickness of 80 microns exposed to 90 and $300 \mathrm{~W} \cdot \mathrm{m}^{-2}$ in the chamber of the MHE device at a sample temperature of $55^{\circ} \mathrm{C}$. The absorbance at $1713 \mathrm{~cm}^{-1}$ was measured and plotted as a function of the exposure time. Figure 2 shows the obtained results.

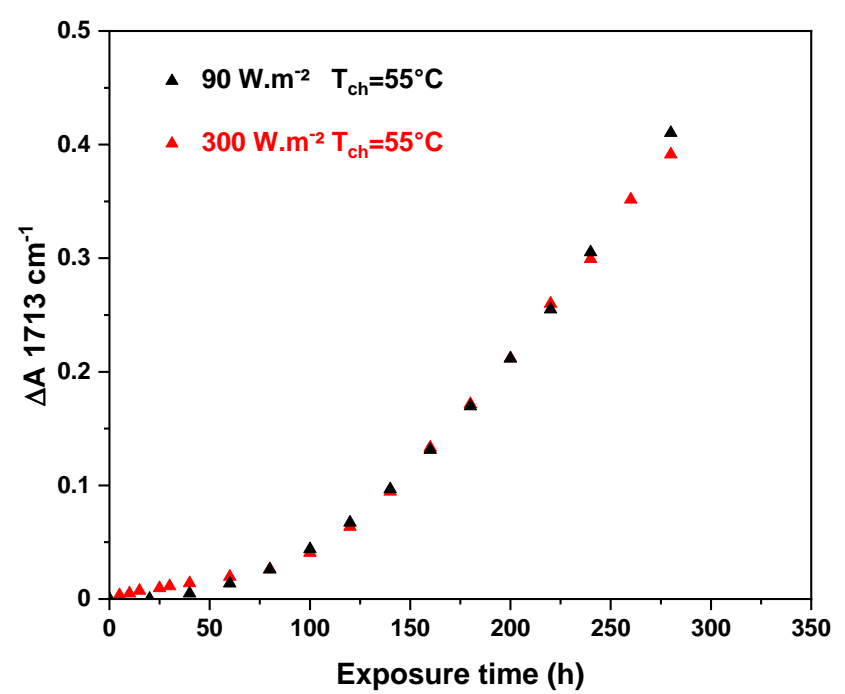

Figure 2: Carbonyl absorbance $\Delta A\left(1713 \mathrm{~cm}^{-1}\right)$ vs. ageing time as a function of irradiance $\left(90\right.$ and $\left.300 \mathrm{~W} \cdot \mathrm{m}^{-2}\right)$ at a sample temperature of $55^{\circ} \mathrm{C}$ (LLDPE film thickness 80 microns).

Unexpectedly, it was observed that the kinetic curves obtained from exposing the samples to two different irradiances $\left(90\right.$ and $300 \mathrm{~W} \cdot \mathrm{m}^{-2}$ ) at the same temperature were the same. This result indicated that no acceleration of the photooxidation was observed, although the irradiance increased by a factor of approximately 3 . 


\subsection{Influence of the film thickness}

This result could be caused by heterogeneous oxidation of the LLDPE film. Heterogeneous oxidation of polymers is a very well-known phenomenon, which has been reported many times in the literature $[10,11,37,38]$. As recalled in the introduction, the most widespread cause of heterogeneous degradation at the macroscopic level results from oxygen diffusion-limited effects. These effects can be observed in the conditions of accelerated ageing, since the rate of oxygen consumption resulting from the oxidative processes induced by light could exceed the rate of oxygen permeation. In this case, oxidation would occur in the surface layers, whereas the core would remain practically unoxidized. Infrared spectroscopy offers the great advantage of being able to monitor the effects of heterogeneous oxidation. Two simple analytic methods can be used: one is based on the use of micro-FTIR spectroscopy and consists of analysing a microtomed shaving of the photooxidized sample obtained in a plane perpendicular to the axis of irradiation $[39,40]$. Another method, which was used here, consists of measuring the intensity of an oxidation band as a function of the thickness of the film [41]. If the absorbance varies linearly with the thickness (for reasonably oxidized samples), the oxidation is expected to be homogeneous in the film. In the case of heterogeneous oxidation, a deviation from linearity is observed above a definite thickness.

Here, we used the second method and exposed to irradiation a series of LLDPE samples with thicknesses varying from 50 microns to 170 microns. The samples were irradiated in the MHE device at 90 and $300 \mathrm{~W} \cdot \mathrm{m}^{-2}$ at $55^{\circ} \mathrm{C}$. As an example, Figure 3 shows the changes in the absorbance at 1713 $\mathrm{cm}^{-1}$ of the LLDPE films with various thicknesses during photooxidation in the MHE device irradiated at $90 \mathrm{~W} \cdot \mathrm{m}^{-2}$ after various times of exposure.

a) 


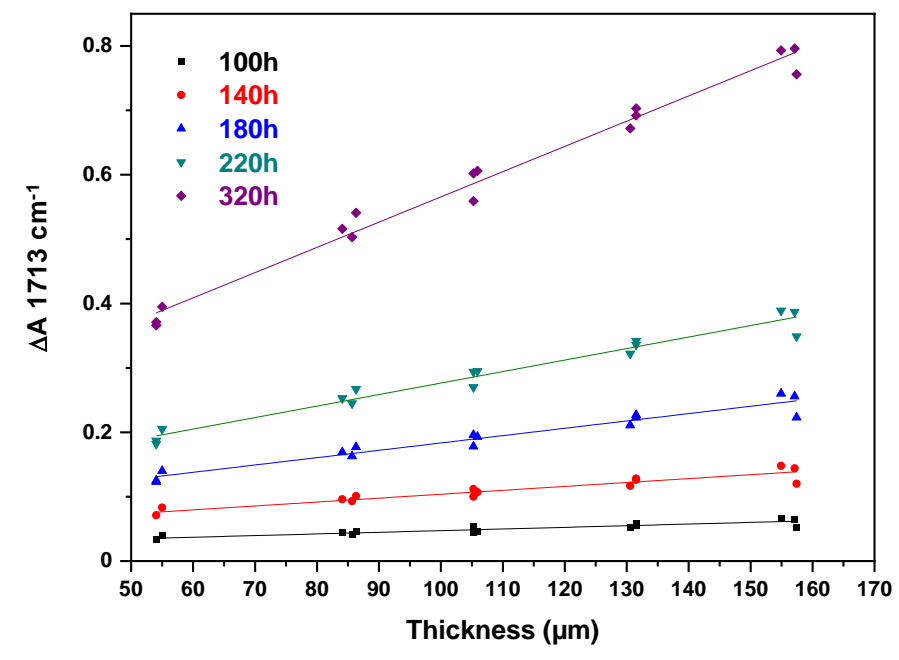

b)

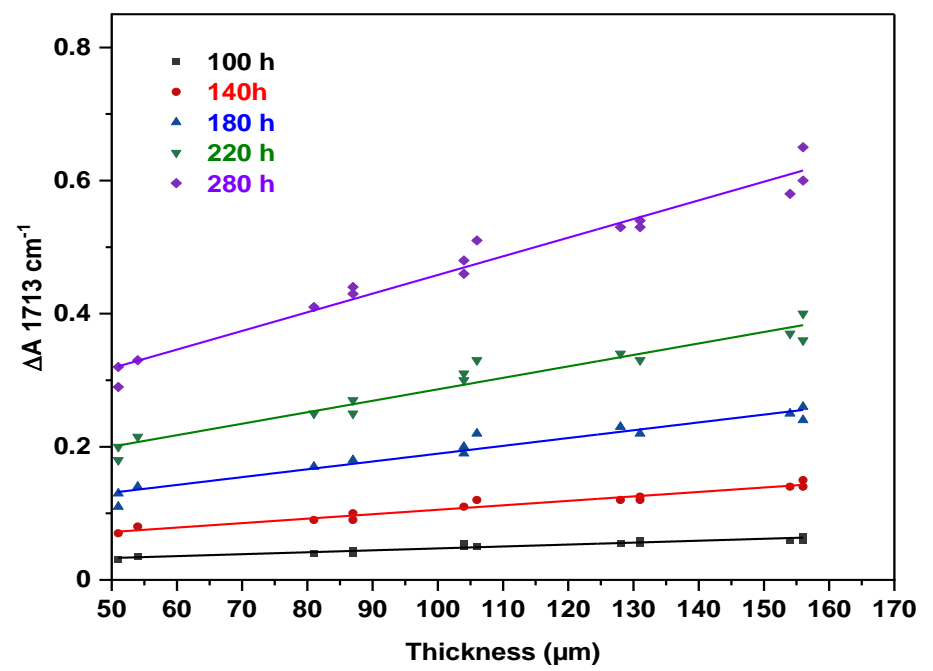

Figure 3: Changes in absorbance at $1713 \mathrm{~cm}^{-1}$ of the LLDPE films with thicknesses from 50 to 170 microns during photooxidation in the MHE device at $55^{\circ} \mathrm{C}$ a) at $90 \mathrm{~W} \cdot \mathrm{m}^{-2}$ and b) and at $300 \mathrm{~W} \cdot \mathrm{m}^{-2}$

This graph shows that the absorbance at $1713 \mathrm{~cm}^{-1}$ after various exposure times from 100 to 320 hours varied linearly with the thickness of the samples. We obtained exactly the same curves in the case of exposures at 90 W.m. $\mathrm{m}^{-2}$ (Fig. 3a) and at $300 \mathrm{~W} \cdot \mathrm{m}^{-2}$ (Fig. 3b). The intercepts of the curves presented in these figures are not equal to 0 , which is a consequence of photo-initiating oxidation products concentrated in a thin layer of the order of 10 microns thick near the surface, as a 
consequence of a surface oxidation during film fabrication, as already reported by Gugumus [42]. This result indicates that the oxidation rate was not controlled by the diffusion of oxygen into the sample.

\subsection{Influence of the temperature $\left(51\right.$ to $\left.65^{\circ} \mathrm{C}\right)$}

We then examined the influence of the temperature of the chamber on the rate of photothermal degradation. The samples were exposed to either 90 or $300 \mathrm{~W} \cdot \mathrm{m}^{-2}$ light, and the temperature was varied from 51 to $65^{\circ} \mathrm{C}$. The kinetic curves of the oxidation are shown in Figure 4 .

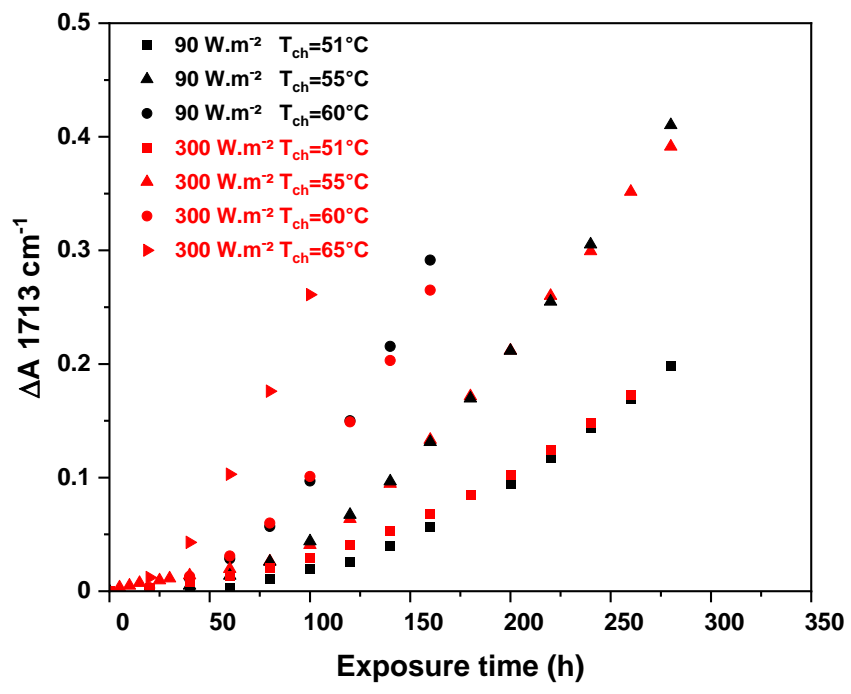

Figure 4: Absorbance $\Delta \mathrm{A}\left(1713 \mathrm{~cm}^{-1}\right)$ vs. exposure time as a function of irradiance (90 and $300 \mathrm{~W} \cdot \mathrm{m}^{-2}$ ) at a sample temperature varying from 51 to $65^{\circ} \mathrm{C}$ (film thickness 80 microns).

The results in Figure 4 show that increasing the temperature during photooxidation experiments led to a marked increase in the rate of oxidation of the sample, which reflected the thermal activation of the photooxidation. From this graph, a shift factor can be easily calculated using the curve at the lowest temperature $\left(51^{\circ} \mathrm{C}\right)$ as the reference. Plotting the logarithm of the shift factor as a function of the inverse of the temperature $1 / T$ allows determining the activation energy, which is proportional to the slope of the linear line fitted through the actual values (Figure 5). The calculated activation

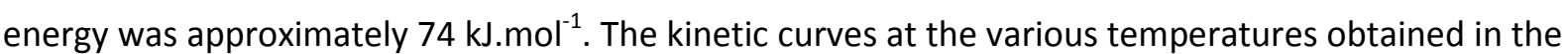
case of irradiations at 90 and $300 \mathrm{~W} . \mathrm{m}^{-2}$ were exactly the same, this then gives the same activation energy for both the irradiances. 


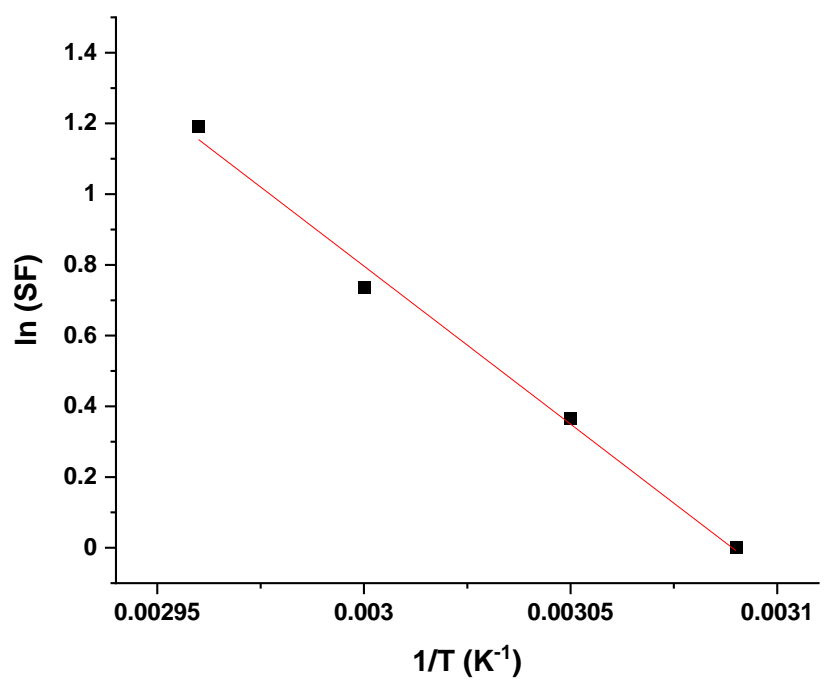

Figure 5: Arrhenius plot of the shift factor (SF) calculated from Figure 4 for LLDPE photooxidation at $300 \mathrm{~W} \cdot \mathrm{m}^{-2}$.

This value was different from that measured in the case of the thermooxidation of polyethylene (in the absence of UV irradiation). A previous study [30] and other studies [9, 43] indicated that, depending on the type of polyethylene (crystallinity, degree of branching, etc.) and the criteria chosen for the Arrhenius plot, the apparent activation energy $E_{a}$ of the linear part of the Arrhenius curve was approximately 100-110 kJ.mol ${ }^{-1}$.

\subsection{Influence of irradiance (below $90 \mathrm{~W} \cdot \mathrm{m}^{-2}$ ) at a constant temperature $\left(60^{\circ} \mathrm{C}\right)$}

The results shown in Figure 2 indicate that no increase in the photooxidation rate was observed when increasing the irradiance from 90 to $300 \mathrm{~W} \cdot \mathrm{m}^{-2}$, which suggests that the Schwarzschild coefficient for LLDPE is equal to 0 in the irradiance range of $90-300 \mathrm{~W} \cdot \mathrm{m}^{-2}$. The next step was to monitor the irradiance dependence of the oxidation rate at irradiances below $90 \mathrm{~W} \cdot \mathrm{m}^{-2}$. We performed experiments using density filters to evenly decrease the irradiance in the whole spectrum without changing the spectral distribution (see Table 1 in the experimental part). Using these filters allowed us to decrease the light irradiance well below $90 \mathrm{~W} \cdot \mathrm{m}^{-2}$. The obtained results are shown in Figure 6. 


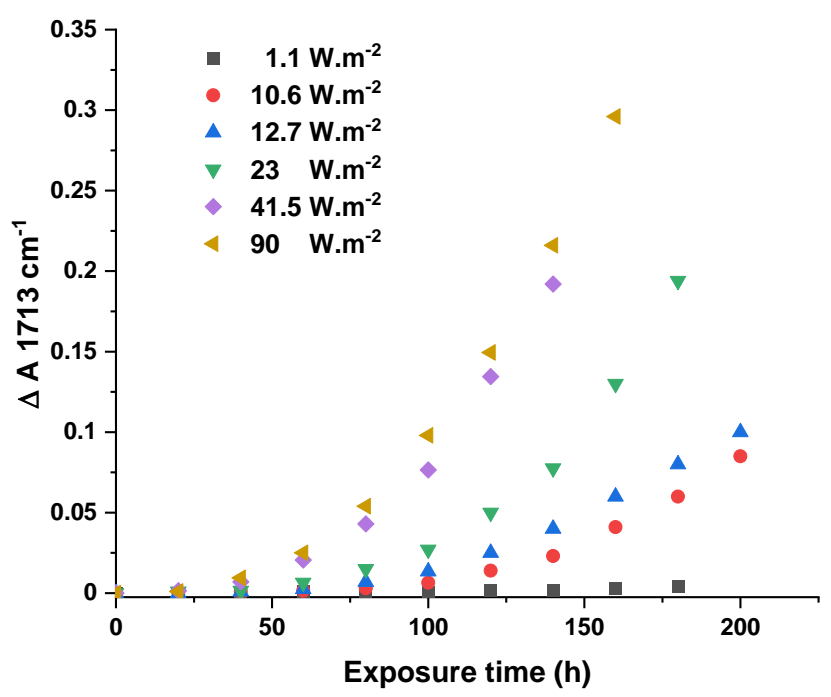

Figure 6: Variations in absorbance $\Delta A\left(1713 \mathrm{~cm}^{-1}\right)$ vs. exposure time as a function of irradiance (0 to $\left.90 \mathrm{~W} . \mathrm{m}^{-2}\right)$ at a sample temperature of $60^{\circ} \mathrm{C}$ (film thickness 80 microns)

These results indicated that the rate of oxidation increased with increasing irradiance, but only in the range of irradiance between 1.1 and $41.5 \mathrm{~W} . \mathrm{m}^{-2}$. It can be observed that the kinetics curves approach a limit when the irradiance exceeds an irradiance value of approximately $50 \mathrm{~W} . \mathrm{m}^{-2}$. This observation indicated that the Schwarzschild coefficient for LLDPE was 0 when the irradiances exceeded this value. From the kinetic curves given in Figure 6 , it is possible to calculate for each irradiance a relative rate, which is defined as the time required to reach a certain absorbance at $1713 \mathrm{~cm}^{-1}$, divided by the time to reach the same absorbance when irradiations were performed at 90 or 300 W. $\mathrm{m}^{-2}$ (it is recalled that the kinetic curves of oxidation were exactly similar at 90 or $300 \mathrm{~W} . \mathrm{m}^{-2}$ ). This was done for three extents of oxidation, corresponding to absorbances $\Delta \mathrm{A}\left(1713 \mathrm{~cm}^{-1}\right)=0.05,0.10$ and 0.15 . The relative rates of photothermal oxidation were then plotted against the irradiance as a $\log -\log$ plot according to the equation $\mathrm{k}=\mathrm{A} \mathrm{I}$. This plot is shown in Figure 7. The slope of the curves in Figure 7 was equal to $p$. The slope was practically the same for the three oxidation extents considered $\left(\Delta \mathrm{A} 1713 \mathrm{~cm}^{-1}=0.05 / 0.10 / 0.15\right)$. The slope approached 0.5 at irradiances below 41.5 W. $\mathrm{m}^{-2}$ and decreased to 0 when the irradiance exceeded $90 \mathrm{~W} \cdot \mathrm{m}^{-2}$. 


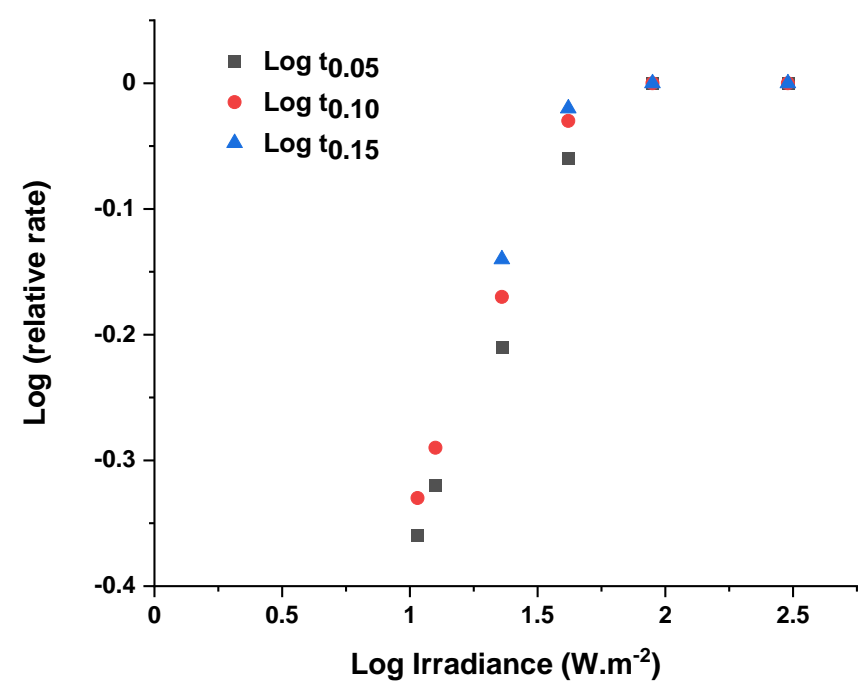

Figure 7 : Relative rates of photothermal oxidation as a $\log -\log$ plot according to the equation $k=A I^{p}$ (the curves correspond to $\mathrm{A}\left(1713 \mathrm{~cm}^{-1}\right)=0.05 / 0.10 / 0.15$

This result was unexpected, and we reproduced this experiment using two other LLDPEs of different origins. The results (not presented here) were found to be exactly similar. It is worth recalling that the results obtained in this manuscript only concern unstabilized polyethylene, and these conclusions apply only to LLDPE and do not necessarily apply to other materials with different chemical natures or materials with stabilizers.

Our results indicated that the formation of carbonyls resulting from exposure to UV light did not follow the reciprocity law. The Schwarzschild coefficient $p$ was always below 1 and approached 0.5 at irradiances below $41.5 \mathrm{~W} \cdot \mathrm{m}^{-2}$. More importantly, above this irradiance level, the coefficient was equal to 0 , which indicated that increasing the irradiance above $50 \mathrm{~W} \cdot \mathrm{m}^{-2}$ did not provoke any increase in the oxidation rate.

A similar trend regarding the effect of light intensity has been reported in the literature [20] in the case of HDPE, which found a linear variation of the oxidation rate with the irradiance and a limit value of the oxidation rate at the highest intensities. No interpretation was given.

As shown above, this result does not result from a limitation of the diffusion of oxygen from the atmosphere into the samples. A plausible explanation considers that above a certain level of UV light intensity, the free radical generation is so high that recombination and/or disproportionation are faster than propagation. Similar trends have been reported in the literature by Gugumus [42] and explained by the fact that when increasing light intensity, the only reactions to be expected were photoreactions of radicals and termination reactions. This result was not expected because an 
irradiance of $90 \mathrm{~W} \cdot \mathrm{m}^{-2}$ in the range of 300 and $415 \mathrm{~nm}$ is generally considered not too high.

Moreover, the second important result is the role played by the temperature, which has not been discussed so far here. The impact of temperature on the rate of photothermal oxidation must be considered since it can fully modify the global scheme. The results shown in Figure 4 indicated that increasing the temperature increased the rate of photothermal oxidation, whereas increasing the irradiance from 90 to $300 \mathrm{~W} \cdot \mathrm{m}^{-2}$ had no effect on the rates. The pure photochemical reactions involved in the initiation and ramification steps are not expected to be thermally activated, whereas propagation is a thermal process. Our results suggested that increasing the temperature favoured the propagation step, after which oxidation became possible. The plausible role that the temperature could play in this process has been reported in the literature [42].

\subsection{Influence of irradiance (90 and $300 \mathrm{~W} \cdot \mathrm{m}^{-2}$ ) on the photothermal oxidation of PC and PET at} a constant temperature $\left(60^{\circ} \mathrm{C}\right)$

Because the results obtained in the case of LLDPE were not expected and could be considered questionable, we repeated the experiments performed with bis-phenol A polycarbonate and poly(ethyleneterephthalate). These polymers were chosen because both have intrinsic absorptions in the UV domain of solar light, which are likely to involve direct photochemical processes. The PC and PET films were exposed to similar irradiance conditions of irradiance $\left(90\right.$ and $300 \mathrm{~W} . \mathrm{m}^{-2}$ ) at a temperature of $60^{\circ} \mathrm{C}$. The oxidation kinetic curves are shown in Figure $8 \mathrm{a}$ and $8 \mathrm{~b}$.

a)

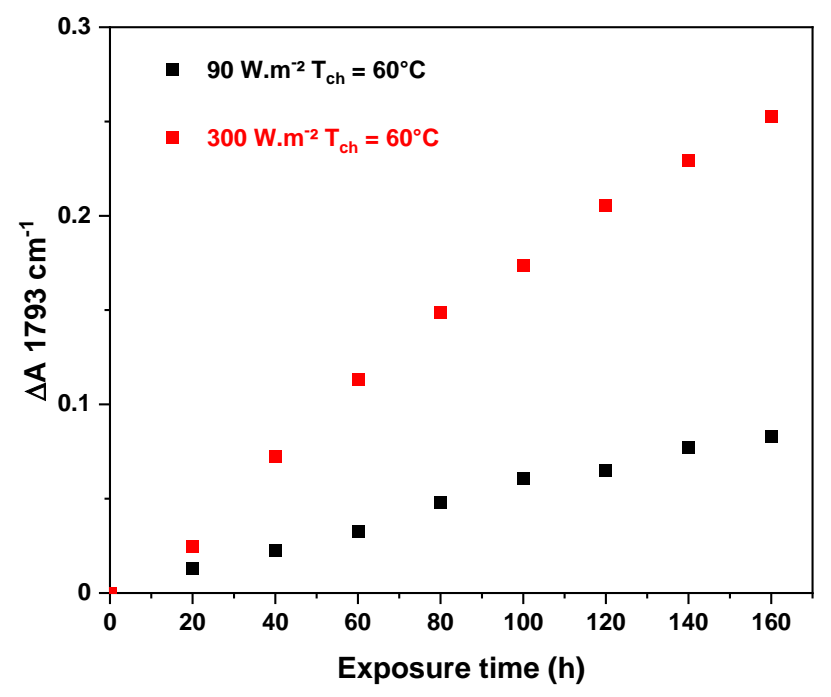

b) 


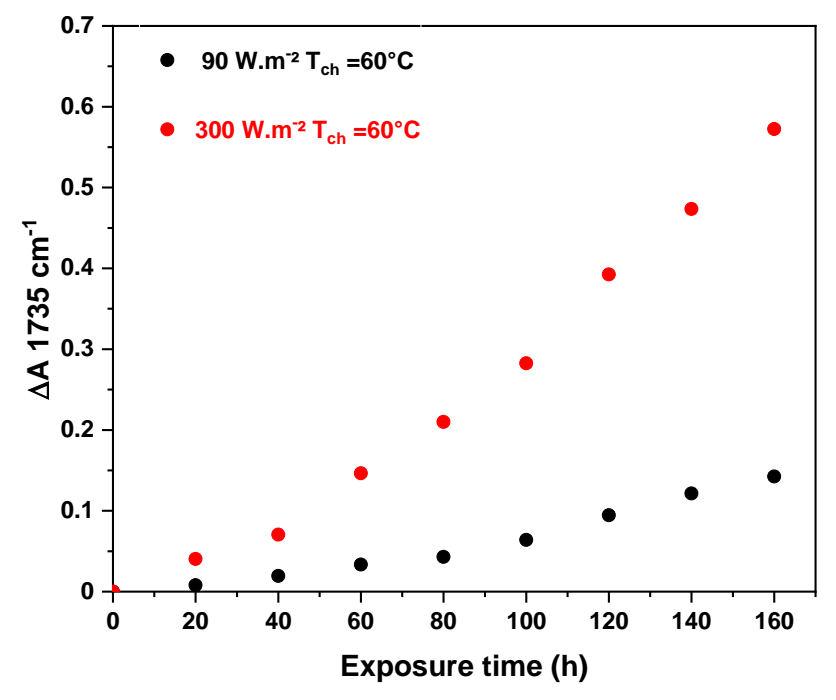

Figure 8: Variation of carbonyl absorbance vs. exposure time as a function of irradiance $\left(90\right.$ and $300 \mathrm{~W} . \mathrm{m}^{-2}$ ) at a sample temperature of $60^{\circ} \mathrm{C}(8 \mathrm{a}: \mathrm{PET}$ and $8 \mathrm{~b}: \mathrm{PC})$

The $p$ coefficients were calculated from the curves in Figure 8 using the same procedure as described above for LLDPE. In the case of PET, the $p$ coefficient was equal to 1 , which implied that the reciprocity was verified (in this range of irradiance). In the case of PC, the $p$ coefficient was approximately 0.8 , which is close to data from the literature $[21,22]$ Linear increases in degradation with increased irradiance were observed for PC and poly(butylene terephthalate) irradiated in Weather-ometer at various irradiances [21] and PC was reported to follow the reciprocity law in the case of irradiations performed at various intensities in a Suntest XXL+ [22]. The comparison of polyethylene with absorbing polymers is an important result which indicates that acceleration is polymer type dependent.

\section{Conclusions}

Accelerating degradation has been desired and explored for years, but it must be considered that the Schwarzschild coefficient $\mathrm{p}$ may vary from one given polymer to another, which is well known; however, it may also vary for a given polymer depending on the stability of the material brought by stabilizers. In the case of unstabilized polyethylene, no acceleration of the oxidation can be obtained by increasing the irradiance above a certain level not considered as high. Reciprocity failure with a $p$ 
from 0.5 to 0 occurs when increasing the irradiance while staying in a range of acceptable irradiance values.

On the basis of results published in the literature [42], this could be explained by the fact that recombination and/or disproportionation are faster than propagation as a result of excessive free radical generation resulting from light absorption at high irradiance levels. Acceleration of the oxidation can be obtained by increasing the temperature because propagation is thermally activated. The pure photochemical processes of polyethylene photooxidation are not thermally activated, in contrast to propagation, which does not involve light.

This result is important from a fundamental point of view, since it shows that the respective roles of light and temperature have to be discriminated. The result is also important from a practical point of view, since it provides strong indications regarding the limits of accelerated ageing and lifetime prediction. Our results indicated that there was a limit to the acceleration. Above a certain irradiance, no more acceleration occurred, but increasing the temperature allowed for an increase in the oxidation rate. However, this result could give more importance to the thermoinduced activation, which could provoke changes in the mechanism. It is indeed known that thermooxidation and photooxidation of LLDPE involve slightly different chemical mechanisms, with different consequences concerning the degradation of the functional properties of the polymer. The results obtained in the case of LLDPE highlight the issue of lifetime prediction, and a comprehensive study should include experiments performed at various irradiances and temperatures, which is timeconsuming and not feasible for obvious reasons.

\section{Acknowledgments}

The financial support of the Agence Nationale de la Recherche through the program LabCom POPBA is greatly appreciated. 


\section{Figure Captions}

Figure 1: Infrared spectra of a LLDPE film (80 microns) at different times of photooxidation in the MHE device $\left(90 \mathrm{~W} \cdot \mathrm{m}^{-2}\right.$ and $\left.60^{\circ} \mathrm{C}\right)$

Figure 2: Carbonyl absorbance $\Delta \mathrm{A}\left(1713 \mathrm{~cm}^{-1}\right)$ vs. ageing time as a function of irradiance $\left(90\right.$ and $\left.300 \mathrm{~W} . \mathrm{m}^{-2}\right)$ at a sample temperature of $55^{\circ} \mathrm{C}$ (LLDPE film thickness 80 microns).

Figure 3: Changes in absorbance at $1713 \mathrm{~cm}^{-1}$ of the LLDPE films with thicknesses from 50 to 170 microns during photooxidation in the MHE device at $55^{\circ} \mathrm{C}$ a) at $90 \mathrm{~W} \cdot \mathrm{m}^{-2}$ and b) and at $300 \mathrm{~W} \cdot \mathrm{m}^{-2}$

Figure 4: Absorbance $\Delta A\left(1713 \mathrm{~cm}^{-1}\right)$ vs. exposure time as a function of irradiance $\left(90\right.$ and $\left.300 \mathrm{~W} \cdot \mathrm{m}^{-2}\right)$ at a sample temperature varying from 51 to $65^{\circ} \mathrm{C}$ (film thickness 80 microns).

Figure 5: Arrhenius plot of the shift factor (SF) calculated from Figure 4 for LLDPE photooxidation at 300 W.m 2.

Figure 6: Variations in absorbance $\Delta A\left(1713 \mathrm{~cm}^{-1}\right)$ vs. exposure time as a function of irradiance $\left(0\right.$ to $\left.90 \mathrm{~W} . \mathrm{m}^{-2}\right)$ at a sample temperature of $60^{\circ} \mathrm{C}$ (film thickness 80 microns)

Figure 7 : Relative rates of photothermal oxidation as a $\log -\log$ plot according to the equation $k=A I^{p}$ (the curves correspond to $\mathrm{A}\left(1713 \mathrm{~cm}^{-1}\right)=0.05 / 0.10 / 0.15$

Figure 8: Variation of carbonyl absorbance vs. exposure time as a function of irradiance (90 and 300 W. $\left.\mathrm{m}^{-2}\right)$ at a sample temperature of $60^{\circ} \mathrm{C}(8 \mathrm{a}: \mathrm{PET}$ and $8 \mathrm{~b}: \mathrm{PC})$

Table 1 : Spectral characteristics of the neutral density filters and irradiance received by the films. 


\section{REFERENCES}

${ }^{1}$ Avenel C., Raccurt O., Gardette J.-L., Therias S. Review of accelerated ageing test modelling and its application to solar mirrors. Solar Energy Materials and Solar Cells 2018;186: 29-41.

${ }^{2}$ Avenel C., Raccurt O., Gardette J.-L., Therias S. Accelerated aging test modeling applied to solar mirrors. npj Materials Degradation, volume 3, 2019; 3: Article number: 27

${ }^{3}$ Torikai A, Mitsuoka T, Fueki K. Wavelength sensitivity of the photoinduced reaction in polycarbonate. Journal of Polymer Science: Part A: Polymer Chemistry 1993; 31:2785-2788.

${ }^{4}$ Andrady AL. Wavelength sensitivity in polymer photodegradation. Advances in Polymer Science 1997; 128:47-94.

${ }^{5}$ Gardette J.L., Lemaire Wavelength effects on the photo-chemistry of poly(vinyl chloride). Polym Degrad Stab 1986; 16: 147-158.

${ }^{6}$ Gaumet S., Gardette J.L., Lemaire J. Photo-chemistry of copolymers of vinylidene chloride and vinyl chloride: Part I-Wavelength effects on discoloration. Polym Degrad Stab 1987; 18: 135-143.

${ }^{7}$ Lemaire J., Gardette J.L., Lacoste J., Delprat P., Vaillant D. Mechanisms of photooxidation of polyolefins : prediction of lifetime in weathering conditions. Adv. Chem. Sci. 1996; 249: 577-598.

${ }^{8}$ Celina M.. Review of polymer oxidation and its relationship with materials performance and lifetime prediction. Polym Degrad Stab 2013; 98:2419-2429.

${ }^{9}$ Celina M, Gillen KT, Assink RA. Accelerated aging and lifetime prediction: review of non-Arrhenius behaviour due to two competing processes. Polym Degrad Stab 2005; 90: 395-404.

${ }^{10}$ Clough R.L., Gillen K.T., Oxygen diffusion effects in thermally aged elastomers. Polym Degrad Stab 1992; 38: 47-5.

${ }^{11}$ Pospısil J., Pilar J., Billingham N.C., Marek A., Horak Z., Nespurek S. Factors affecting accelerated testing of polymer photostability. Polym Degrad Stab 2006; 91 :417-422.

${ }^{12}$ Rivaton A, Sallet D, Lemaire J. The photochemistry of bisphenol A polycarbonate reconsidered. Polymer Photochemistry 1983; 3: 463-81.

${ }^{13}$ Lemaire J, Gardette JL, Rivaton A, Roger A. Dual photochemistries in aliphatic polyamides, bisphenol A polycarbonate and aromatic polyurethanes - a short review. Polym Degrad Stab 1986; 15:1-13.

${ }^{14}$ Rivaton A. Recent advances in bisphenol A polycarbonate photodegradation. Polym Degrad Stab 1995; 49:163-79.

${ }^{15}$ Philippart J.L., Sinturel C., Gardette J.L. Influence of the light intensity on the photooxidation of polypropylene. Polym Degrad Stab 1997; 58: 261-268

${ }^{16}$ Philippart J.L., Sinturel C., Arnaud R., Gardette J.L. Influence of the exposure parameters on the mechanism of photooxidation of polypropylene. Polym Degrad Stab 1999; 64: 213-225

${ }^{17}$ Pimentel Real L., Gardette J.L., Rocha A.P. Artificial Simulated and Natural Weathering of Polyvinylchloride for Outdoor Applications: the Influence of the Water in the changes of properties. Polym Degrad Stab 2005, 88, 357-362

${ }^{18}$ Martin J.W., Chin J. W., Nguyen T. Reciprocity law experiments in polymeric photodegradation:a critical review. Progress in Organic Coatings 2003;47: 292-311

${ }^{19}$ S. W. Bigger, J. Scheirs, O. Delatycki. Effect of light Intensity on the Photooxidation Kinetics of High-Density Polyethylene. J. Polym. Sci. Part A: Polym. Chem.: Vol. 30 (1992)

${ }^{20}$ Fairbrother A., Hsueh H.C., Kim J.H., Jacobs D., Perry L., Goodwin D., White C., Watson S., Sung L.P. Temperature and light intensity effects on photodegradation of high-density polyethylene. Polym Degrad Stab 2019; 165: 153-160

${ }^{21}$ Pickett J.E., Gibson D.A., Gardner M.M.. Effects of irradiation conditions on the weathering of engineering thermoplastic Polym Degrad Stab 2008; 93: 1597-1606.

${ }^{22}$ Diepens M., Gijsman P.. Influence of light intensity on the photodegradation of bisphenol-A polycarbonate. Polym Degrad Stab 2009; 94: 34-38.

${ }^{23}$ Gaumet J., Gardette J.L., Lemaire J.Photo-oxidation of poly(vinylchloride): 2. A comparative study of thermoand photo-oxidations. Polym Degrad Stab 1991; 33: 17-34. 
${ }^{24}$ Pazur R., Troquet M., Gardette J.L. Photo- and thermooxidation of poly(isobutylene)- Part 1 : evolutions at temperature above $50^{\circ} \mathrm{C}$. J Polym Sci 1997; 1689-1701.

${ }^{25}$ Phillipart J.L., Gardette J.L. Thermooxidation of i-PP in ${ }^{32} \mathrm{O}_{2^{-}}{ }^{36} \mathrm{O}_{2}$ : comparison of the mechanisms of thermoand photo-oxidation. Polym Degrad Stab 2001; 73: 185-187.

${ }^{26}$ Schwarzschild K., On the law of reciprocity for bromide of silver gelatin. Astrophys. J. 1900; 11: 89.

${ }^{27}$ Pickett J.E., Gibson D.A., Gardner M.M., Effects of irradiation conditions on the weathering of engineering thermoplastics. Polym Degrad Stab 2008; 93: 1597-1606.

${ }^{28}$ Pickett J. E., Kuvshinnikova O., Sung L.P., B. Ermi. D. Accelerated weathering parameters for some aromatic engineering thermoplastics. Polym Degrad Stab 2019; 166: 135-144.

${ }^{29}$ Larché J.-F., Bussiere P.-O., Therias S., Gardette J.-L. Photoxidation of polymers: Relating material properties to chemical changes. Polym Degrad Stab 2012; 97: 25-34.

${ }^{30}$ Rapp G., Tireau J., Bussiere P.O., Chenal J.M., Rousset F., Chazeau L., Gardette J.L., Therias S. Influence of the physical state of a polymer blend on thermal ageing, Polym Degrad Stab 2019; 163: 161-173.

${ }^{31}$ Gardette JL in Handbook of Polymer Degradation. S. Halim Hamid Ed. (Marcel Dekker, Inc.). 2000; 699-726.

${ }^{32}$ Ginhac J.M., Gardette J.L., Arnaud R., Lemaire J. Influence of hydroperoxides on the photothermal oxidation of polyethylene. Makromol Chem, 1981; 182: 1017-1025.

${ }^{33}$ Chakraborty K.B., Scott G. The effects of thermal processing on the thermal oxidative and photo-oxidative stability of low density polyethylene, Eur. Polym. J. 1977; 13: 731-737.

${ }^{34}$ Geetha R., Torikai A., Nagaya S., Fueki K. Photo-oxidative degradation of polyethylene: Effect of polymer characteristics on chemical changes and mechanical properties. Part 1-Quenched polyethylene, Polym Degrad Stab 1987;19: 279-292.

${ }^{35}$ Chirinos-Padrón A.J., Hernández P. H., Chávez E., Allen N.S., Vasiliou C., De Poortere M. Influences of unsaturation and metal impurities on the oxidative degradation of high density polyethylene. Europ Polym J, 1987; 23, 12: 935-940.

${ }^{36}$ Carpentieri I, Brunella V, Bracco P, Paganini C, Brach del Prever EM, Luda MP, Bonomi S, Costa L. Postirradiation oxidation of different polyethylenes. Polym Degrad Stab 2011; 96 :624629.

${ }^{37}$ Cunliffe A.V, Davis A. Photooxidation of thick polymer samples. Part II : The influence of oxygen diffusion on the natural and artificial weathering of polyolefins. Polym Degrad Stab 1982; 4: 17-37.

${ }^{38}$ Gillen K.T., Clough R.L. Techniques for monitoring heterogeneous oxidation of polymers. In : N.P. Cheremisinoff, ed. Handbook of Polymer Science and Technology. New-York: Marcel Dekker, 1989, pp. 167202.

${ }^{39}$ Jouan X., Gardette J.L. Development of a micro(FTIR)spectrometric method for characterization of heterogeneities in polymer films. Polymer 1987; 28: 329-331.

${ }^{40}$ Gardette J.L.. Micro(FTIR) spectroscopic profiling of aged polymer films. Spectroscopy Europe 1993; 5 : 28-32.

${ }^{41}$ Gardette J.L., Philippart J.L.. Perturbation of the photochemistry of poly(vinylchloride) by a conventional aromatic plasticizer. J Photochem Photobiol A 1988; 43 : 221-231.

${ }^{42}$ Gugumus F., Photooxidation of polyethylene films, 1: Experimental kinetics of functional group formation, Die Angewandte Makromolekulare Chemie 1990; 182: 85-109.

${ }^{43}$ Khelidj N., Colin X., Audouin L., Verdu J., Monchy-Leroy C., Prunier V. Oxidation of polyethylene under irradiation at low temperature and low dose rate. Part II. Low temperature thermal oxidation, Polym Degrad Stab 2006; 91 :1598-1605. 